\title{
Developing a Mobile App for Learning English Vocabulary in an Open Distance Learning Context
}

\author{
Mpine Makoe and Thuli Shandu \\ University of South Africa (UNISA)
}

\begin{abstract}
Academic success depends on the comprehension of a language, which is linked to vocabulary learning. Many distance students in South Africa find it difficult to comprehend learning in a language other than their mother tongue. Finding effective strategies for enhancing English vocabulary of university students amidst the spatial, temporal, and pedagogic distance associated with Open Distance Learning (ODL) practices remains a challenge. To address the need for enhancing vocabulary development, mobile application systems (apps) were explored as the best vehicle for the delivery of the vocabulary learning. Mobile learning technologies are ideal in the ODL context because they are flexible, accessible, available, and cater for a myriad of interaction activities. The purpose of the study is to design and implement a mobile-based application aimed at enhancing English vocabulary teaching and learning. Using the Design-Based Research methodology, this study maps the steps taken to develop a vocabulary learning mobile app named VocUp; it describes the architecture, user interface, features of VocUp, and advocates for contextually-conscious and learning-driven app development.
\end{abstract}

Keywords: mobile apps, vocabulary teaching and learning, android app development, design-based research 


\section{Introduction}

Mobile phones have proliferated our daily lives to an extent that many confess to not being able to live without them. Inasmuch as they were earlier touted as wireless communication devices that allowed for untethered, anytime, and anywhere calls, mobile phones are now complex instruments with multiple functions (Godwin-Jones, 2011). Within the language learning sphere, mobile application systems (apps) have transformed the mobile phone into mobile language laboratories where users can learn and practise languages wherever and whenever they find an opportunity (Kukulska-Hulme, 2009; Traxler, 2009). This flexibility in learning is especially critical in Open Distance Learning (ODL) contexts where students, often with limited time and resources, need a flexible mode of learning that allows them to study anywhere and anytime. The spatial and temporal distance in ODL often means that the students are separated from their peers, instructors, and even the institutional physical resources such as the library (Moore, 1993; Makoe, 2010). Therefore, there is a crucial need for support not only for learning, but also for language learning and use.

Supporting language learning is critical in South Africa given that students, whose first language is often not English, are expected to be proficient in English as an academic language. Many of these students struggle to meet the academic demands of higher education because their academic success is determined, mostly, by their proficiency in English. Academic success, according to Folse (2010) "depends on reading ability, and reading ability is in turn strongly linked to vocabulary" (p. 140). However, second language speakers find it difficult to comprehend learning in a language other than their mother tongue. Comprehension is linked to one's vocabulary as Nation (2002) reported that an educated native speaker of English knows about 20,000 word families, or 70,000 words, but second or foreign language students of English know only a fraction of this number (Laufer \& Yano, 2001). Studies have shown that increased vocabulary positively influences academic performance (Larsen-Freeman, 2003; Nation, 2002; Nation \& Waring, 1997). Finding effective strategies for enhancing the vocabulary of university students amidst the spatial, temporal, and pedagogic distance is, therefore, a major challenge in ODL.

To address the distance students' need for vocabulary learning, mobile application systems (apps) were explored as the best vehicle for the delivery of the vocabulary learning. Mobile learning technologies are ideal in the ODL context because they are flexible, available, and cater for a myriad of interaction activities. The idea is to harness the affordances of mobile technology that is synonymous to the students' lifestyle by presenting a portable programme that is accessible to students anytime and anywhere. Therefore, the purpose of this study is to design and implement a mobile-based application aimed at enhancing vocabulary teaching and learning.

\section{Vocabulary Teaching and Learning}

For many years, vocabulary teaching was not considered a critical component of language learning as reading and grammar (de Groot, 2006). One school of thought has expressed that vocabulary can be picked up incidentally when learners are exposed to other activities such as reading (Ender, 2014), while others have supported the view that vocabulary should be purposefully and explicitly taught (Feldman \& Kinsella, 2005). According to Nation's (2002) multi-componential framework for teaching vocabulary, there are three dimensions of word knowledge: form, meaning, and use. Students need to learn the form of words, their meaning, and how to use them appropriately in various settings. The multi-componential nature of word knowledge was used to ground this study because it provides a much needed structure for how to teach vocabulary within a distance learning context. 
The first principle of vocabulary development is the explicit teaching and learning of vocabulary, which refers to the "selection and presentation of words for learners" (Furneaux, 1999, p. 367). This also involves directly teaching learners how to internalise and use the vocabulary because "merely giving students lists of words to learn is certainly not effective vocabulary instruction." (Oxford \& Scarcella, 1994, p. 231). The second principle of vocabulary teaching pertains to practice through repeated exposure to the vocabulary and opportunities for rehearsals. It was therefore important that the mobile app should facilitate repeated exposure to words used previously. The third principle relates to testing. According to Stockwell (2010) and Zimmerman (1997), incorporating exercises as part of vocabulary learning leads to effective vocabulary development. It is therefore important that assessment is incorporated in the proposed app so that distance students could demonstrate their grasp of the new words. The aim of using mobile apps is to facilitate interaction between student and a teacher, and among students themselves. Interaction plays a crucial role in education especially in vocabulary teaching and learning where students are expected to use the new vocabulary in real life, including interaction with the content, device, teacher, and other students.

The feasibility of interaction in its varied forms is difficult in an ODL context due to the physical as well as pedagogic distance between students and the learning environment. Throughout the history of distance education, different types of technologies have been explored to address the concept of interaction which is vital for success in education. There are different types of interaction in ODL, the main ones being student-student interaction and student-lecturer interaction, as well as studentcontent interaction (Moore, 1993). These interactions are all underpinned by the crucial role of technology in facilitating meaningful interaction (Garrison, 1989). Distance learning students need continuous interaction which is facilitated by the lecturer and, thus, requires technology that will be continuously accessible for students and lecturers (Makoe, 2010). The decision to use mobile phones to enhance interaction for teaching vocabulary was influenced by three factors: context, availability, and accessibility. Mobile phones were chosen because they offers space that makes interaction and attention to vocabulary possible, even in ODL contexts.

The context in which learning takes place is critical, according to Cole (2003), because it is located within a social environment that influences an individual in a various ways. Therefore, it is important that the pedagogical principles should be guided by the context of teaching and learning. In this context, learning will be guided by the principles of the ODL practice, the accessibility of mobile phones in the South African environment, and the students learning experiences. In an ODL context, there is a need to facilitate teaching to students who are learning at a distance. Therefore, the delivery of teaching should be flexible so that students can access them anytime and anywhere.

The lack of infrastructure to support Information Communication Technologies (ICTs) in most developing countries, has led to the proliferation of the wireless infrastructure. The use of mobile phones in Africa has increased at an alarming rate. In South Africa alone, the ownership of cellphones was just over 85 million, while the population is about 45 million in 2015 (Shezi, 2016). In this context, owning a mobile phone is not a luxury, but "a staple of day-to-day life" for all spheres of society (Pandey \& Singh, 2015, p. 108). This shows that mobile phones are available and accessible to a large number of people and therefore can be used to facilitate teaching and learning. According to Keegan (2005), "It is not technologies with inherent pedagogical capabilities that are successful in distance education, but technologies that are generally available to citizens" (p. 3). Therefore, vocabulary learning through content and device interaction is best facilitated and augmented by mobile learning technologies because they are flexible, available, and cater for countless interaction activities (Traxler, 2009). 


\section{Design-Based Research Methodology}

Since mobile phones have transcended the function of making and receiving calls and they are now a learning tool, they are used to support ODL students as they learn English vocabulary. The idea was to harness the affordances of mobile technologies that students were already familiar with to enhance their vocabulary. To address the objective of the study, the Design-Based Research (DBR) methodology was used because of its devotion to the development of interventions that solve problems in authentic contexts (Anderson \& Shattuck, 2012). DBR is concerned with integrating known and hypothetical design principles with technological affordances towards practical solutions; conducting rigorous and reflective inquiry to test and refine innovative learning environments as well as to define new design principles (Anderson \& Shattuck, 2012; Kolmos, 2015).

In developing the mobile app for teaching and learning vocabulary, the four-phased DBR methodology was followed. The first phase relied on the literature review and the analysis of context to identify and analyse the problem. The second phase involved the development of a solution using existing vocabulary teaching and learning principles. The third phase of the DBR is preoccupied with evaluation and testing of the solution in practice (McKenney \& Reeves, 2013). Since DBR is concerned with improved interventions and principles for real educational environments, this phase involves a series of iterative cycles of testing and refinement. The iterations leads to the fourth stage of DBR in the form of a reflection to produce design principles and enhance solution implementation.

Once it was determined that a mobile vocabulary app would be the best intervention, a search for a relevant app that focused on vocabulary learning was done through surveying language learning apps. Some of the apps provided in-depth explicit teaching of vocabulary that included synonyms and antonyms. Other apps provided images and visual cues as part of vocabulary teaching and resources, such as pictures of the words taught. Yet other apps provided daily vocabulary delivered to the user together with definitions and examples of how that word had been used in literature, but they did not provide opportunities for testing understanding. Some apps were tailored in that they were aimed at providing preparation for specific standardised tests. Despite the myriad apps available in the market, none was considered appropriate for the purposes of vocabulary learning in ODL because they could not facilitate the principles which underpin the pedagogy of vocabulary teaching and learning. Given the limitations of the surveyed apps, a contextually relevant app was then developed to address the pedagogical (content) thrust and the technological (vehicle) delivery. The app had to conform to the vocabulary learning principles of explicit vocabulary teaching (Nation, 2002); rehearsal and practice as well as incorporating testing (Stockwell, 2010).

\section{Developing the App}

Using the benefits of the portability of the device; the different features in the device; the multimedia functionality of voice, text, and graphic-audio visual, had made it possible for mlearning to cater for innovative ways to teaching and learning especially in an ODL context. The mobile devices are not only accessible, they are also less expensive than computers and laptops and they are cheaper to charge so that students where electricity is scarce, can keep their phones operating. Its accessibility, availability, and flexibility are the underlying and foregrounding principles that makes mlearning to be considered as more beneficial over other delivery tools of learning.

Planning. The first step towards planning for the development of the mobile app meant to enhance vocabulary learning is to decide on the content that was to be taught. Research has emphasized 
the importance of developing a language learning environment before deciding on the role of mobile technologies and further emphasizes a focus on the learner ahead of the technology (Salaberry, 2001; Colpaert, 2004); therefore, there was a need for ensuring a match between pedagogy and technology (Sweeney \& Moore, 2012). In this case, the mobile app was developed to enhance vocabulary learning. There was a need for increased vocabulary towards increased proficiency and better chances of success (Schmitt, Schmitt, \& Clapham, 2001), thus it was decided that vocabulary would be taught in its multicomponential nature of form, meaning, and use (Larsen-Freeman, 2003; Nation \& Waring, 1997). Further, the content had to conform to the vocabulary principles of explicit teaching, repeated exposure, as well as assessment practices. Based on the work of Thornton and Houser (2002), short lessons were created which were labelled Word Capsules. Each Word Capsule contains the word of the day, part of speech, definition, three sentences for different ways the word could be used in real contexts, and three exercises for further testing and application.

The second step was to identify the operating system for the envisaged mobile app. Three operating systems were considered for developing the native app including the IOS, Android, and Symbian. The Android Operating System was selected because, according to Joorabchi, Mesbah, and Kruchten (2013), there were about two million apps available with Android taking 52\% of the market; Apple taking 38\% of market share, and AppWorld and Windows with 6\% and 3\% respectively. The app was developed on the open source platform with a complete software stack for a mobile device.

The third step was to draw mockups of what the app was to look like on the phone. The app development software was then installed on the computer as part of setting up the environment for Android app development. Different programmes were installed for creating the app where all codes for instructions were entered and others were meant to enable the computer to understand and "speak" the language of the app. Other programmes were emulators, which enables the developer to see how the app will look like in a real android phone.

Coding. Following the planning stage was the coding process which focused on three main sections including developing the User Interface (UI), creating Activities, as well as creating Activity Life Cycles. Developing the UI involved creating the packaging of the app, its view, and layout. The linear layout and card view were used because they displayed the different sections of the vocabulary in a logical and presentable flow. Other features such as background colours, font colours, and special characters, including bold and italic, were also coded.

The Activities of the app were sections which form part of the app and these were divided into four activities. The Word of the Day activity has subcategories of reflecting the word itself; part of speech and definition. The next Activity has the Examples which listed three sentences reflecting how a word can be used in real life. The third Activity is the Exercises which was a list of three questions giving the users an opportunity to test their grasp of the vocabulary and further allow for vocabulary use. Each exercise has the question itself, three options, one correct answer, and a check button. The last Activity contains Past Words, a list of words which have been covered in previous days so the users can go back and review them.

The Activity Life Cycle involved coding instructions for what the app had to do and when. The app was given instructions on what to do when a phone has been switched off and then on; when the app has been inactive; when the user closes the app (onCreate, onStart, onResume- Running, Paused, Stopped). These instructions included background activities for the app to connect periodically to the cloud to pull 
down updates such as new Word Capsules. Other programmes were used binding the Activities and keeping them in sync while testing if the instructions were being applied.

Adding vocabulary content. To develop Word Capsules, words were carefully selected from the two versions of the Vocabulary Levels Test (Schmitt et al., 2001). The 10,000 word levels from both versions of the test were used because language learners who have grasped the most frequent 10,000 words in English have a wide vocabulary and may be able to cope with the challenges of studying at university in English.

Short vocabulary lessons were created and labelled as Word Capsules. To illustrate the concept of a word capsule, the word "bask" is used. After detailing that this entry as a "verb," a definition is entered as "To sit or lie enjoying the warmth, usually exposed to the sun, for relaxation. Bask is also used to mean deriving pleasure especially from attention.” Then three sentences exemplifying use are presented as:

1. Take care to wear sunscreen as you bask in the sun this summer.

2. My sister basked in the limelight as she received awards for sports excellence.

3. I've had it with her indolence; she spends her days basking in the sun when she should be helping me with chores.

The word usage examples are followed by exercises which provide more opportunities for using the new word and also to test understanding:

1. Which of the following songs would you most likely associate with bask?
a. I'm gonna soak up the sun
b. Ain't no sunshine when she's gone
c. Crying in the sun

2. Choose a feeling that best goes together with basking.
a. Irritation
b. Fear
c. Joy

3. Another word for bask could be
a. Burn
b. Sleep
c. Revel 
App testing. When the app looked and worked well, it was sent to external parties for testing. Feedback was received on the technical aspects of the app, such as ease of use as well as the content such as typos, options, and answers to exercises. The comments were used to revise the app through a series of testing and revisions.

VocUp overview. Once the app was developed, it was given the name VocUp as a play on "upping the vocabulary" which would sound a bit like "vocabulary app." A VocUp icon was then created that would make the app identifiable on the phone. After downloading and running the app, the user could click on the VocUp link to access the Word of the Day. Alternatively, if the user allows it, the app sends a notification to the user when the new word is delivered in the morning. This feature is meant to invite the busy ODL student to take some time and do some studying. The app was developed as selfsufficient to encourage independent study.

App evaluation and discussion. To inform the design principles, VocUp was evaluated in relation to its technological design and how it facilitated vocabulary learning as an intervention. Although the purpose of VocUp is vocabulary development, it is also important for the delivery tool to be of quality for it to fulfil the purpose for which it was created. According to Parsons, Ryu, and Cranshaw (2007), quality in a mobile learning system should focus on product quality and the quality of the user experience. They further assert that mobile learning environment issues pertain to user role and profile, mobility, interface design, media types, communication support, as well as the elimination of technical errors (Parsons et al., 2007). Pertinent to the issues of quality is the device aspect, the intersection of device usability, and social technology. To evaluate the technology aspects of VocUp, Sarrab, Elbasir, and Alnaeli's (2016) quality model was used because it has synthesised previous quality models and took into account the recent developments in mobile technologies. In the words of Sarrab et al. (2016), the model provides "developers with concrete actions that will reach the preferred quality level" (p. 101).

While it was developed based on the principles of vocabulary development, including the explicit teaching of form, meaning, and use; repeated exposure to learned words; as well as assessment practices (Folse, 2006; Nation, 2002), VocUp coheres to the technical qualities pertaining to mobile learning (Sarrab et al., 2016). The quality checks included availability, flexibility, quick response, connectivity, reliability, functionality, usability, and security. Table 1 presents the list of mobile technical aspects in relation to VocUp.

Table 1

Towards A Quality Model of Technical Aspects for Mobile Learning Services With Added VocUp Features

\begin{tabular}{|l|l|l|}
\hline Technical aspect & Short description & VocUp examples \\
\hline Availability & $\begin{array}{l}\text { Accessibility associated with } \\
\text { mlearning. }\end{array}$ & $\begin{array}{l}\text { - Word capsules sent early in the } \\
\text { morning. } \\
\text { - Past words accessible in the app } \\
\text { for revisiting and reviewing. }\end{array}$ \\
\hline Quick response & Avoiding delays in response. & $\begin{array}{l}\text { - Downloading and access prompt } \\
\text { due to data size. }\end{array}$ \\
\hline
\end{tabular}




\begin{tabular}{|c|c|c|}
\hline & & $\begin{array}{l}\text { - Exercises quickly alert user of } \\
\text { incorrect answer. }\end{array}$ \\
\hline Flexibility & Offering options for the user. & $\begin{array}{l}\text { - Flexibility of time and place of } \\
\text { use. } \\
\text { - Content flexibility. }\end{array}$ \\
\hline Scalability & $\begin{array}{l}\text { Accommodating changes made } \\
\text { to the system. }\end{array}$ & $\begin{array}{l}\text { - Accommodated later changes on } \\
\text { alarms and activities. } \\
\text { - Migrated system to new hosting } \\
\text { site. }\end{array}$ \\
\hline Connectivity & $\begin{array}{l}\text { Maintaining connectedness for } \\
\text { collaboration through instant } \\
\text { interactivity. }\end{array}$ & Learner-device interaction. \\
\hline Reliability & $\begin{array}{l}\text { Consistency and trusted } \\
\text { functioning without system } \\
\text { failure. }\end{array}$ & $\begin{array}{l}\text { - Reliability affected by system } \\
\text { error and bugs at the beginning. } \\
\text { - System correction and bug clean- } \\
\text { up improved reliability. }\end{array}$ \\
\hline Functionality & $\begin{array}{l}\text { Accuracy and suitability of the } \\
\text { app based on the needs of the } \\
\text { users and their contexts. }\end{array}$ & $\begin{array}{l}\text { - VocUp teaches vocabulary } \\
\text { explicitly. } \\
\text { - The app functions such as } \\
\text { notifications improve functionality. }\end{array}$ \\
\hline Usability & Ease of use. & $\begin{array}{l}\text { - Sliding screens between activities. } \\
\text { - Accessing word of the day and } \\
\text { past words. }\end{array}$ \\
\hline Security & $\begin{array}{l}\text { Achieving data confidentiality, } \\
\text { integrity, and availability. }\end{array}$ & $\begin{array}{l}\text { - VocUp does not carry high-risk } \\
\text { confidential information such as } \\
\text { student numbers and academic } \\
\text { records or bank account details. }\end{array}$ \\
\hline
\end{tabular}

Note. The table illustrates the various technical aspects towards quality in mobile learning, qualified through VocUp features aligning to relevant quality markers. Adapted from "Towards a quality model of technical aspects for mobile learning services: An empirical investigation," by M. Sarrab, M. Elbasir, and S. Alnaeli, 2016, Computers in Human Behavior, 55(A), p. 101. Copyright 2015 by Elsevier Ltd.

\section{Testing the App}

Once the app was developed, tested, and piloted to a small number of people, VocUp was then disseminated to a group of first-year English students who had signed consent forms to participate in the study. The app, together with a set of instructions on how to download, was sent to the participants through WhatsApp. After downloading it onto their phones, the participants began to engage with the vocabulary immediately. The word of the day had different categories for the word on each screen. The main screen had the word of the day including the part of speech and definition. Sliding the screen showed the three example sentences. Another slide showed the exercises. On the second day, the app sent the new word with the different screens showing the various categories of the word. The previous 
day's word was available in the Past Words screen. After a few weeks of activity with VocUp, interview questions were sent to participants and their responses sent back to the researcher on WhatsApp. The interview questions were related to the participants' experiences of downloading and using VocUp with particular references to the technical aspects, as well as the pedagogical issues pertaining to the app. The interview questions were sent individually to all the participants and 18 out of 29 participants sent back their responses.

One of the characteristics of DBR is that it is situated in real educational contexts and therefore participants were asked to respond on their experiences on using VocUp and how it could be improved. Based on the virtual interviews, the results showed benefits related to ease of use, familiarity with phone systems, and vocabulary content. Participants appreciated the fact that the app was interactive in that the exercises helped them to get prompt feedback on assessing their understanding of the content. In the absence of human-human interaction, the app provided device-human interaction that facilitated feedback. Since most distance students have responsibilities besides studying, they said the app's notifications were helpful because it served as a constant reminder to engage in learning. Despite these benefits, the findings revealed that the challenges of VocUp related to phone problems, network and connectivity, as well as a lack of familiarity with phone use. Some participants were wary of downloading VocUp, as they feared it might be costly. Other participants were concerned about the security of the app. The one area of concern was that VocUp was downloaded through a link to a website where the app code was stored. Failure to pay attention to protection and security can hinder the adoption and use of a mobile app such as VocUp.

Although VocUp facilitated student-content and student-device interaction where the participants appreciated the privacy of working alone, other participants felt that they needed student-student and student-lecturer interaction. It was clear that the refinement needed to include an interaction component to it. VocUp was created with the purpose of assisting distance students to learn new words at their own pace. The exercises, as multiple-choice or sentence and paragraph writing, also was meant to facilitate the cognitive presence processes as some exercises prompted a sense of puzzlement, which necessitated cognitive engagement with the words. The exercises also played a socio-emotional role in that the participants were elated and had their confidence boosted, or were shy and sometimes dejected based on when and how they answered the exercises. Not only did this vocabulary app serve a reflective role of testing the grasp of learned vocabulary, but the assessment also served the role of facilitating interaction. The assessment was so important that the participants requested more exercises to be included as part of the intervention. The use of mobile phones meant that the participants could continue with their daily lives while they also caught up on vocabulary.

VocUp refinement. Since DBR is about refinement of the solution, the results from the first interviews assisted with the refinement of the app. The main refinement areas were technical and pedagogic in nature. Although some students were able to download the app easily and quickly, others who were not familiar with the phone and the app system struggled a bit. This indicated that the instructions for downloading the app needed refinement so that downloads would be easier since distance students work mostly on their own. In addition to refined instructions, the participants requested the inclusion of a word pronunciation feature. While the participants in this study had one word per day, with three main sections of the lesson focusing on form, meaning, and use, participants also wanted more exercises in addition to the activities they completed. This was a surprising given that distance students have to juggle their studies with personal, work, family, and social commitments. However, this finding reveals that distance students know what they want, aware of their vocabulary 
deficiencies, and want more support in developing their vocabulary. The need for more work may be that participants enjoyed accessing lessons from a medium that was not disruptive of their daily activities. The vocabulary learning technology was integrated into their lifestyle and they could conveniently access the content.

\section{Reflection and Discussion}

The final phase in design of the app began with what had to be taught, how it had to be taught, to whom, when, and how. The "what" question was lucidly responded to by the importance of vocabulary in language proficiency, especially for second language speakers. As to what exactly needed to be taught as part of the vocabulary, Larsen-Freeman (2003) provided guidance on teaching form, meaning, and use. There was also a need to teach students how to spell the word correctly, define it, and use it appropriately. Regarding the specific vocabulary to be taught, the Vocabulary Levels Test (Schmitt et al., 2001) were used because it had gone through stringent validity and reliability processes. From the Test, words were selected to form Word Capsules, which would explicitly teach vocabulary while the app facilitated repeated exposure to words and provided assessment opportunities. The interaction between user and device was one of the most useful and helpful features of the app, especially in the ODL context. The exercises provided student-device and student-content interaction where feedback was received immediately and prompted the users to attempt the question again, or opt to revisit the other sections as they became aware of gaps in understanding.

The appeal of mobile learning is the fact that one uses a tool with which most students are familiar. In this study, thus, the mobile phone proved to be both a resource and a source of frustration. It was a resource because it provided flexible and easy access to the content, but it was a frustration and barrier when the device seemed to hinder their ability to access content, such as when there was no network. Familiarity with technology or lack thereof, even after orientation, determined whether one would be able to access the content or participate successfully in the intervention. This study revealed that challenges and shortcomings associated with mlearning are actually related to the users' comfort and familiarity with the technology used. It is therefore important that practitioners consider developing context-appropriate apps that serve the needs of their students.

\section{Conclusion}

This paper has highlighted the importance of technological, as well pedagogical, aspects of mobile-app interventions for vocabulary teaching and learning. In planning to implement mobile learning, this study demonstrated a need for interventions to consider the teaching and learning context in addition to the students for whom the interventions are developed. In trying to implement mlearning, effort should be made to incorporate interventions that would not further exclude students from benefiting. In this study, the intervention for vocabulary development was developed within the contextual principles of ODL, which emphasise student-centredness, flexibility, and accessibility. There was a marked effort to create technologically-stable and pedagogically sound intervention that would benefit students. When developing mobile apps, however, we should be cautious of being presumptuous about student backgrounds by creating interventions as all-encompassing; instead, we should be prudent and offer options to students. Mobile apps that will work in ODL, therefore, are those that acknowledge 
contextual variables, provide options for independent study, and/or interaction. To facilitate studentcentredness, interventions should be flexible and accessible. 


\section{References}

Anderson, T., \& Shattuck, J. (2012). Design-based research: A decade of progress in education research? Educational Researcher, 41(1), 1-17. https://doi:10.3102/0013189X11428813

Cole, M. (2003). Vygotsky and context. Where did the connection come from and what difference does it make? Istanbul: International Society for Theoretical Psychology. Retrieved from http://lchc.ucsd.edu/People/MCole/lsvcontext.html

Colpaert, J. (2004). From courseware to coursewear? Computer Assisted Language Learning, 17(34), 261-266. https://doi/abs/10.1080/0958822042000319575

De Groot, A. (2006). Effects of stimulus characteristics and background music on foreign language vocabulary learning and forgetting. Language Learning, 56(3), 463-506.

doi/abs/10.1111/j.1467-9922.2006.00374.x

Ender, A. (2014). Implicit and explicit cognitive processes in incidental vocabulary acquisition. Applied Linguistics, 37(4), 536-560. https://doi.org/10.1093/applin/amu051

Feldman, K., \& Kinsella, K. (2005). Narrowing the language gap: The case for explicit vocabulary instruction. Scholastic. Retrieved from http://teacher.scholastic.com/products/authors/pdfs/Narrowing the Gap.pdf

Folse, K. (2010). Is explicit vocabulary focus the reading teacher's job? Reading in a Foreign Language, 22(1), 139-160. Retrieved from http://files.eric.ed.gov/fulltext/EJ887885.pdf

Furneaux, C. (1999). Recent materials on teaching writing. ELT Journal, 53(1), 56-61. https://doi.org/10.1093/elt/53.1.56

Garrison, D. R. (1985). Three generations of technological innovations in distance education. Distance Education, 6(2), 235-241. https://doi.org/10.1080/0158791850060208

Godwin-Jones, R. (2011). Emerging technologies: Mobile apps for language learning. Language Learning \& Technology, 15(2), 2-11.

Joorabchi, M. E., Mesbah, A., \& Kruchten, P. (2013, October). Real challenges in mobile app development. In The ACM/IEEE International Symposium on Empirical Software Engineering and Measurement (pp. 15-24). IEEE.

https://doi.org/10.1109/ESEM.2013.9

Keegan, D. (2005, October). The incorporation of mobile learning into mainstream education and training. In Proceedings of the 4th World Conference on m-Learning, Cape Town, (pp. 2528). Retrieved from keegan1.pdff?AWSAccessKeyId=AKIAIWOWYYGZ2Y53UL3A\&Expires=15369358 $53 \&$ Signature incorporation of mobile learning int.pdf

Kolmos, A. (2015, July). Design-based research: Issues in connecting theory, research and practice. In Research in Engineering Education Symposium (pp. 13-15). Aungier St.: Dublin Institute of 
Technology. Retrieved from http://vbn.aau.dlk/en/publications/designbasedresearch--issues-in-connecting-theory-research-and-practice(d4a34757-95ba4801-90e9-34468a56a844).html

Kukulska-Hulme, A. (2009). Will mobile learning change language learning? ReCALL, 21(2), 157-165. https://doi.org/10.1017/S0958344009000202

Larsen-Freeman, D. (2003). Teaching language: From grammar to grammaring. Boston: Heinle.

Laufer, B., \& Yano, Y. (2001). Understanding unfamiliar words in a text: Do L2 learners understand how much they don't understand? Reading in a Foreign Language, 13(2), 549-566.

Makoe, M. (2010). Exploring the use of MXit: A cell-phone social network to facilitate learning in distance education. Open Learning, 25(3), 251-257. https://doi.org/10.1080/02680513.2010.512099

McKenney, S., \& Reeves, T. (2013). Educational design research. In M. Spector, M. Merrill, J. Elen, \& M. Bischop (Eds.), Handbook of research on educational communications \& technology. London: Springer.

Moore, M. G. (1993). Theory of transactional distance. In D. Keegan (Ed.), Theoretical principles of distance education (pp. 22-38). Routledge: London.

Nation, P. (2002). Best Practice in Vocabulary Teaching and Learning. In J. Richards \& W. Renandya (Eds.), Methodology in Language Teaching: An Anthology of Current Practice, (pp. 267272). Cambridge: Cambridge University Press. https://doi.org/10.1017/CB09780511667190.037

Nation, P., \& Waring, R. (1997). Vocabulary size, text coverage and word lists. Vocabulary: Description, Acquisition and Pedagogy, 14, 6-19. Retrieved from http://catdir.loc.gov/catdir/samples/cam031/97042211.pdf

Oxford, R. L., \& Scarcella, R. C. (1994). Second language vocabulary learning among adults: State of the art in vocabulary instruction. System, 22(2), 231-243. https://doi.org/10.1016/0346251X(94)90059-0

Pandey, K., \& Singh, N. (2015). Mobile learning: Critical pedagogy to education for all. In Y. Zhang (Ed.), Handbook of Mobile Teaching and Learning, (pp. 107-132). Heidelberg, Berlin: Springer. https://doi:10.1007/978-3-642-54146-9 6

Parsons, D., Ryu, H., \& Cranshaw, M. (2007). A design requirements framework for mobile learning environments. Journal of Computers, 2(4), 96-100. DOI: 10.4304/jep.2.4.1-8

Salaberry, M. R. (2001). The use of technology for second language learning and teaching: A retrospective. The Modern Language Journal, 85(1), 39-56.

https://doi.org/10.1111/0026-7902.00096 
Sarrab, M., Elbasir, M., \& Alnaeli, S. (2016). Towards a quality model of technical aspects for mobile learning services: An empirical investigation. Computers in Human Behavior, 55, 100-112. https://doi.org/10.1016/j.chb.2015.09.003

Schmitt, N., Schmitt, D., \& Clapham, C. (2001). Developing and exploring the behaviour of two new versions of the Vocabulary Levels Test. Language Testing, 18(1), 55-88. DOI: 10.1177/026553220101800103

Shezi, L. (2016, April 29). SA's 26.8 million internet users spend almost three hours a day on social media. HXT. Retrieved from http://www.htxt.co.za/2016/04/29/the-stuff-southafrica-26-8-mil-internet-users-spend-most-their-time-doing-online/

Stockwell, G. (2010). Using mobile phones for vocabulary activities: examining the effect of the platform. Language Learning \& Technology, 14(2), 95-110.

Sweeney, P., \& Moore, C. (2012). Mobile apps for learning vocabulary: Categories, evaluation and design criteria for teachers and developers. International Journal of Computer-Assisted Language Learning and Teaching (IJCALLT), 2(4), 1-16. DOI: 10.4018/ijcallt.2012100101

Thornton, P., \& Houser, C. (2002). M-learning in transit. In P. Lewis (Ed.), The changing face of CALL (pp. 229-243). Lisse, The Netherlands: Swets and Zeitlinger.

Traxler, J. (2009). Current state of mLearning. In M. Ally (Ed.), mLearning: Transforming the delivery of education and training (pp. 9-24). Edmonton, Alberta: Athabasca University Press.

Zimmerman, C. B. (1997). Do reading and interactive vocabulary instruction make a difference? An empirical study. TESOL Quarterly, 31(1), 121-140. https://doi.org/10.2307/3587978

\section{Athabasca University}

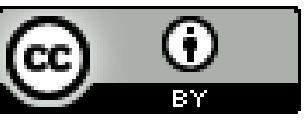

